\title{
Aproximación a las comunidades de carófitos que existieron en la Albufera de Valencia a partir del estudio de las oósporas del sedimento
}

\author{
por \\ María A. Rodrigo ${ }^{1}$, José Luis Alonso-Guillén ${ }^{1}$, Santos Cirujano ${ }^{2}$ \& Ingeborg Soulié-Märsche ${ }^{3}$ \\ ${ }^{1}$ Laboratorio de Ecología Integrativa, Institut Cavanilles de Biodiversitat i Biologia Evolutiva, Universitat de València, \\ Apartado Oficial 2085, E-46071 Valencia, España. maria.a.rodrigo@uv.es, j.luis.alonso@uv.es \\ ${ }^{2}$ Real Jardín Botánico, CSIC. Plaza de Murillo 2, E-28014 Madrid, España. santos@rjb.csic.es \\ ${ }^{3}$ Institut des Sciences de l'Evolution, Paleoenvironments, Université Montpellier II, C.P. 061, Place E. Bataillon, \\ F-34095 Montpellier-Cedex 5, Francia. ingeborg.soulie-marsche@univ-montp2.fr
}

\begin{abstract}
Resumen
Rodrigo, M.A., Alonso-Guillén, J.L., Cirujano, S. \& Soulié-Märsche, I. 2009. Aproximación a las comunidades de carófitos que existieron en la Albufera de Valencia a partir del estudio de las oósporas del sedimento. Anales Jard. Bot. Madrid 66(2): 195-208.

Las oósporas de carófitos y sus características (tamaño, forma, color, ornamentación de la pared, etc.) pueden persistir en los bancos de semillas del sedimento de ecosistemas acuáticos, y pueden ser utilizadas para identificar los diferentes táxones y obtener de este modo una aproximación a la composición florística de las comunidades de carófitos que colonizaron ambientes acuáticos en los que actualmente no existe vegetación acuática o se encuentra muy alterada. La Albufera de Valencia perdió hace muchos años las praderas de carófitos que cubrían sus fondos sin tener un estudio detallado de las mismas. Se han extraído diversos testigos de sedimento en tres puntos de esta laguna, se han caracterizado las oósporas y girogonitos encontrados y se ha estimado la densidad de oósporas-girogonitos en diferentes profundidades del sedimento. En total se han identificado 10 táxones, que corresponden: 6 al género Chara [Ch. vulgaris, Ch. hispida var. major, Ch. fragilis (Ch. globularis), Ch. hispida var. baltica, Ch. aspera y Ch. tomentosa]; una especie de Nitella (N. hyalina); 2 de Tolypella (T. glomerata y T. hispanica), y una de Lamprothamnium (L. papulosum). Esta última, indicadora de la época en la que la laguna poseía una mayor salinidad, se encontró en las capas más profundas del sedimento. Se ha observado un aumento del número y de la diversidad de oósporas en capas más profundas del sedimento, lo que indica, por un lado, que la laguna atravesó distintas fases ecológicas (con importantes cambios de salinidad principalmente) y, por otro, que el proceso de eutrofización que padece la laguna durante al menos los últimos 45 años afectó progresivamente a la abundancia y diversidad de carófitos.
\end{abstract}

Palabras clave: Carófitos, oósporas, la Albufera, Valencia, España, Chara, Nitella, Tolypella, Lamprothamnium.

\begin{abstract}
Rodrigo, M.A., Alonso-Guillén, J.L., Cirujano, S. \& Soulié-Märsche, I. 2009. Former charophyte communities in l'Albufera de València revealed by a study of the sediment bank oospores. Anales Jard. Bot. Madrid 66 (2): 195-208 (in Spanish).

Charophyte oospores and their features (size, shape, colour, outer wall ornamentation, etc.) are able to persist in seed banks of aquatic ecosystems. Thus, these characteristics can be used for taxonomic species identification, thereby providing knowledge about the specific composition of the charophyte community in a habitat that currently lacks, or has greatly altered, submerged vegetation. Several years ago, I'Albufera de València lost the charophyte meadows that covered the lake bottom in the past, which had never been studied in detail. Several sediment cores were extracted from the lagoon at three sites and the oospores and gyrogonites were isolated and characterized. The oospore/gyrogonite densities in the sediment layers were estimated. Ten different taxa have been identified: six belonging to genus Chara [Ch. vulgaris, Ch. hispida var. major, Ch. fragilis (Ch. globularis), Ch. hispida var. baltica, Ch. aspera, Ch. tomentosa]; one Nitella species (N. hyalina), two Tolypella species ( $T$. glomerata and T. hispanica) and one Lamprothamnium species (L. papulosum). The latter, which indicates the period when water salinity was high in the lagoon, was found in the deepest sediment layers. An increase in the oospore abundance and diversity was observed in line with sediment depth. This indicates, on the one hand, that the lagoon went through different ecological stages (with important changes in salinity, mainly) and, on the other hand, the eutrophication process that the lagoon has been undergoing for at least the last 45 years, has progressively affected the abundance and diversity of the charophyte community.
\end{abstract}

Keywords: Charophyte, Oospores, I'Albufera, València, Spain, Chara, Nitella, Tolypella, Lamprothamnium. 


\section{Introducción}

Los carófitos son algas verdes evolucionadas que colonizan ambientes acuáticos distribuidos por todo el mundo (Van de Berg \& al., 1998). Estos organismos son abundantes y frecuentes en los ecosistemas con aguas limpias, pero cuando aumenta la eutrofia son sustituidos por diversas plantas vasculares (Blindow, 1992; Van de Berg \& al., 1998), para finalmente extinguirse cuando la contaminación es elevada (Kufel \& Kufel, 2002) y el desarrollo de los florecimientos de fitoplancton impide la penetración de la luz hacia los fondos de las masas acuáticas.

La Albufera de Valencia es una laguna litoral cuyos fondos, en el pasado, estuvieron cubiertos en su mayor parte por compactas praderas de macrófitos acuáticos, esencialmente de los géneros Chara, Potamogeton, Myriopbyllum y Ceratophyllum (Prósper, 1910; Arévalo, 1916; Pardo, 1942). Hacia los años sesenta del siglo XX empezó un proceso de eutrofización que no ha cesado hasta nuestros días (Dafauce, 1975). Hasta la década de 1990, se vertían directamente a la laguna efluentes urbanos e industriales sin depurar a través de acequias y canales de riego, lo que suponía aproximadamente un $17 \%$ de las entradas anuales, y un $67 \%$ del agua procedía, cargada de nutrientes inorgánicos, de los arrozales próximos (Soria \& Vicente, 2002). Por ello, la Albufera de Valencia pasó, en pocos años, de ser un sistema acuático de aguas limpias y transparentes al actual sistema hipereutrófico y turbio dominado por el fitoplancton (Romo \& al., 2005). Este proceso de eutrofización hizo que la vegetación subacuática desapareciera por completo sin haber sido estudiada con detalle, y solamente disponemos de algunas referencias de los carófitos que colonizaron la laguna (Prósper, 1910; Corillion, 1962; Guerlesquin, 1963; Boira \& Carretero, 1985).

Los estudios realizados con testigos de sedimento permiten reconstruir la historia biológica de los ecosistemas acuáticos a partir de los restos de los organismos que un día los habitaron (Julià \& al., 1998). En los sedimentos recientes se encuentran formas de resistencia de algunos organismos, como huevos de rotíferos (García-Rocher \& al., 2006), de cladóceros (Vandekerkhove \& al., 2005), semillas y otros propágulos vegetales (Combroux \& al., 2001), entre ellos los girogonitos y esporas de carófitos (Van den Berg \& al., 2001; Bonis \& Grillas, 2002; De Winton \& al., 2004). Algunas características morfológicas de las esporas de los carófitos (tamaño, color, ornamentación de la pared, etc.) se conservan durante largos periodos de tiempo en los sedimentos, y permiten identificar los diferentes táxones y obtener de este modo una aproximación a las formaciones vegetales que colonizaron un determinado ecosistema acuático (De Winton \& al., 2000). Por otro lado, las propágulos sexuales de los carófitos han sido reconocidos como una nueva categoría de bioindicadores acuáticos, ya que reflejan las condiciones ambientales en el momento y lugar de su crecimiento, así como las variaciones en las mismas (Soulié-Märsche, 1991; 1998; 2008).

El objetivo principal de este trabajo ha sido la descripción de la comunidad de carófitos que en tiempos pasados albergó la Albufera de Valencia a partir del estudio de las oósporas y girogonitos (oósporas calcificadas) del sedimento de la laguna. Para ello se extrajeron diversos testigos de sedimento y se aislaron, recontaron y caracterizaron las oósporas y girogonitos de los carófitos que antaño cubrían los fondos de la laguna.

\section{Material y métodos}

\section{Área de estudio}

La Albufera de Valencia es una laguna litoral somera (1,2 $\mathrm{m}$ de profundidad media), actualmente oligohalina (salinidad aproximada 1-2\%o) (Soria \& al., 1987; Romo $\&$ al., 2005), con una superficie de $23,2 \mathrm{~km}^{2}$, siendo por tanto la laguna litoral más grande del Estado Español. Desde el siglo XVII se cultiva arroz en las inmediaciones de la laguna (pero la verdadera expansión arrocera comienza en el siglo XVIII y su máximo desarrollo tuvo lugar en el siglo XIX; Sanchis-Ibor, 2001), por lo que el nivel de sus aguas se regula de forma artificial. Este humedal está incluido en la lista de la Convención de Ramsar, creada en esa ciudad de Irán en 1971, es considerada zona ZEPA por su interesante y valiosa fauna ornítica y, tanto la laguna como los arrozales, la restinga arenosa y otros ambientes acuáticos y terrestres quedaron incluidos en el año 1986 dentro del Parc Natural de L'Albufera de València.

Como resultado de su evolución histórica asociada a los usos humanos (Sanchis-Ibor, 2001), la Albufera ha experimentado grandes cambios en la salinidad del agua, pasando de poseer aguas más o menos saladas o salobres hasta los valores actuales de salinidad. Por otro lado, y como cita textualmente Dafauce (1975) en su estudio piloto sobre la Albufera de Valencia: "La Albufera se encuentra inmediatamente amenazada por la creciente eutrofización de sus aguas, ocasionada por el aporte de materia orgánica de origen urbano, agrícola e industrial... Estas impurificaciones empezaron a acusarse hacia 1955, se acentuaron sobre 1965 y en la actualidad [años setenta] alcanzan caracteres alarmantes". Así, las concentraciones de clorofila $a$ en las aguas de la Albufera pasaron de valores medios de 15 g/L en 1972 (Dafauce, 1975; ya era por entonces una laguna mesoeutrófica) a $341 \mu \mathrm{g} / \mathrm{L}$ (Soria, 
Tabla 1. Valores medios (y algunos máximos*) de clorofila a en las aguas de la Albufera de Valencia en diferentes periodos.

\begin{tabular}{|l|c|l|}
\hline Periodo & $\begin{array}{c}\text { Clorofila a } \\
(\mu \mathrm{g} / \mathrm{L})\end{array}$ & \multicolumn{1}{|c|}{ Referencia } \\
\hline 1972 & 15 & Dafauce, 1975 \\
\hline 1973 & 35 & Dafauce, 1975 \\
\hline 1974 & 53 & Dafauce, 1975 \\
\hline 1981 & $800^{*}$ & Serra \& al., 1984 \\
\hline 1983 & $700^{*}$ & Miracle \& al., 1987 \\
\hline $1985-1986$ & 341 & Soria, 1997 \\
\hline $1995-1996$ & 142 & $\begin{array}{l}\text { Datos de la Confederación } \\
\text { Hidrográfica del Júcar y } \\
\text { Conselleria de Medi Ambient, } \\
\text { en Soria, 1997 }\end{array}$ \\
\hline 2008 & 146 & \begin{tabular}{l} 
Datos propios \\
\hline
\end{tabular}
\end{tabular}

1997; hipereutrófica) en el periodo de 1985 a 1988, pasando por máximos de 800 g/L (Serra \& al., 1984) a principios de los años ochenta (Tabla 1$)$.

\section{Toma de los testigos de sedimento y procesado}

En septiembre de 2007 se tomaron tres testigos de sedimento de $55-65 \mathrm{~cm}$ de profundidad con la ayuda de un tubo de metacrilato transparente de $5,5 \mathrm{~cm}$ de diámetro en tres puntos de la laguna (Fig. 1). El criterio de elección de los puntos estuvo basado en la documentación oral de la mayor abundancia de vegetación subacuática en dichas zonas. La primera estación de muestreo (punto 1) estaba localizada en la zona NE, en un área conocida como El Brossar (UTM 30S 07278744359410 ); el segundo testigo (punto 2) se recogió cerca de la mata de Sant Roc (UTM 30 S 07262914357903 ), y el tercero (punto 3) se tomó al W de la mata Manseguerota (UTM 30S 0728307 4356722). Posteriormente, en octubre de 2007, se extrajo un nuevo testigo del punto 1 (de $45 \mathrm{~cm}$ de profundidad), el cual se fraccionó en capas de $3-4 \mathrm{~cm}$, las cuales se guardaron y procesaron separadamente. Finalmente, el 21 de enero de 2008 se tomó un nuevo testigo del punto 1 , esta vez de $87 \mathrm{~cm}$ de profundidad, con un muestreador de sedimentos tipo Beeker (Eijkelkamp) y se seccionó en fracciones de $2 \mathrm{~cm}$ de espesor. La muestras de sedimento se guardaron en oscuridad y refrigeradas hasta el momento de su procesado. Cada sección de $2 \mathrm{~cm}$ de sedimento se homogenizó con una espátula, y una alícuota sirvió para determinar el peso seco tras secado a $70^{\circ} \mathrm{C}$ durante 24 horas. El resto del sedimento se tamizó secuencialmente utilizando varios tamices con mallas de distinto tamaño de poro (1000, 500, 250 y $200 \mu \mathrm{m})$.

\section{Aislamiento, identificación y cuantificación de las oósporas-girogonitos del sedimento}

Las oósporas y girogonitos de los carófitos se aislaron con ayuda de unas pinzas y/o un pincel fino y de un estereomicroscopio Olympus SZ40. De cada oóspora y/o girogonito se tenía en cuenta su tamaño (longitud y anchura), color, forma y ornamentación (número de crestas, estrías de las oósporas y distancia de separación entre ellas, presencia o ausencia de hombro, detalle de la placa basal, forma de la roseta apical [ápex], presencia o ausencia de columna basal, etc.), que son caracteres taxonómicos de diferente valor taxonómico (Haas, 1994). La columna basal es una elongación de longitud variable y de sección pentagonal a cilíndrica localizada en la base de las oósporas y girogonitos. El ápex es la parte, de forma cónica a hemisférica, presente en la zona apical de las oósporas y girogonitos, donde convergen las espiras. Se habla de ápex cóncavo, convexo o plano cuando el espacio presente entre las espiras es cóncavo, convexo o plano, respectivamente. El hombro es una pequeña depresión en la vista lateral de la zona apical, justo bajo el ápex, presente tanto en oósporas como en girogonitos (Haas, 1994). Se calculó el índice de isopolaridad (ISI) (Horn af Rantzien, 1956) así como la relación longitud/anchura $\times 100$ para cada oóspora. En función de las características citadas se asignaron las oósporas-girogonitos a distintas especies y variedades. De cada especie-variedad encontrada se tomaron varios ejemplares para su observación con microscopía electrónica de barrido, a partir de la cual pudo examinarse la ornamentación de la pared de las oósporas. Se utilizó el equipo Hitachi mod. S-4100 del

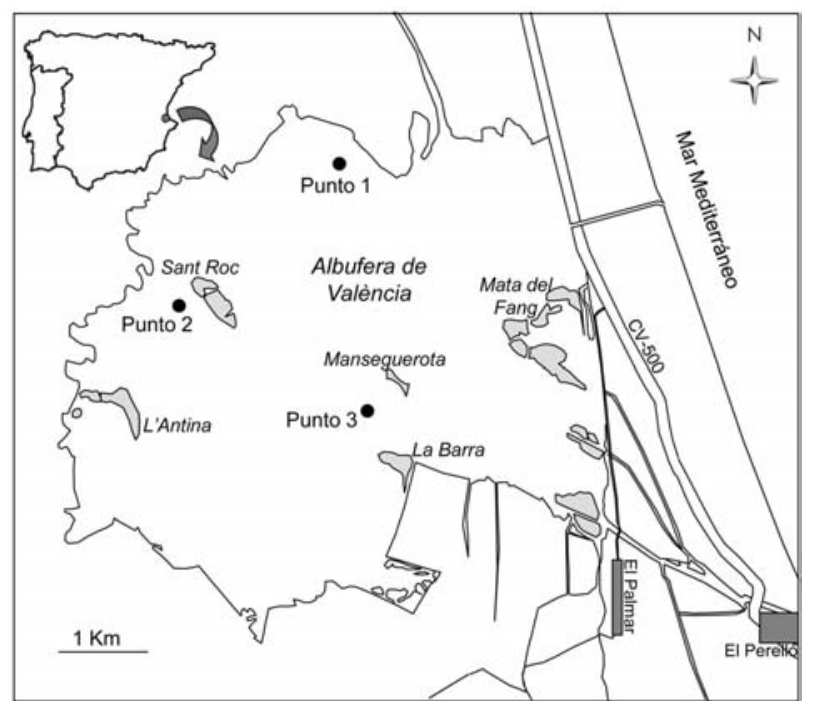

Fig. 1. Ubicación de los puntos de muestreo del sedimento en la Albufera de Valencia. 
M.A. Rodrigo \& al.

\begin{tabular}{|c|c|c|c|c|c|c|c|c|c|c|}
\hline 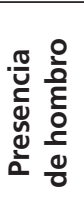 & $\stackrel{\circ}{\simeq}$ & $\bar{n}$ & $\stackrel{\circ}{\simeq}$ & $\bar{\omega}$ & $\stackrel{\circ}{\subseteq}$ & $\bar{n}$ & $\stackrel{\circ}{\subseteq}$ & $\stackrel{\circ}{\complement}$ & $\stackrel{\circ}{\subseteq}$ & 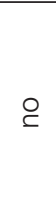 \\
\hline $\begin{array}{l}\frac{\pi}{0} \\
\frac{0}{0} \\
000 \\
0 \\
\frac{\pi}{0} \\
0 \\
0 \\
\frac{0}{0}\end{array}$ & 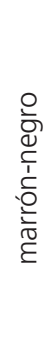 & $\begin{array}{l}\stackrel{\circ}{7} \\
\stackrel{\Phi}{\complement}\end{array}$ & 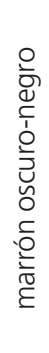 & 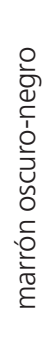 & 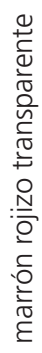 & 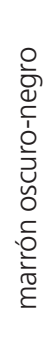 & $\begin{array}{l}\stackrel{\circ}{\square} \\
\stackrel{\Phi}{\complement}\end{array}$ & 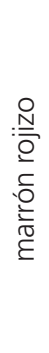 & 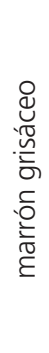 & 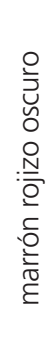 \\
\hline 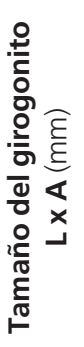 & 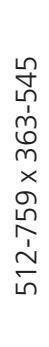 & 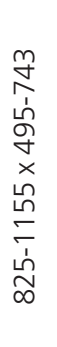 & 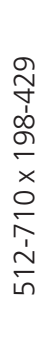 & 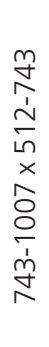 & 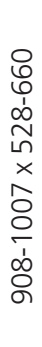 & 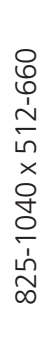 & 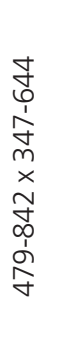 & 1 & 1 & 1 \\
\hline 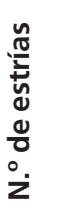 & $\begin{array}{l}\overline{+1} \\
\bar{\tau}\end{array}$ & $\begin{array}{l}\mp+ \\
\stackrel{+}{\simeq}\end{array}$ & $\begin{array}{l}\bar{r} \\
\stackrel{m}{m}\end{array}$ & $\begin{array}{l}\stackrel{+}{+} \\
\stackrel{\sim}{\simeq}\end{array}$ & $\begin{array}{l}+ \\
+1 \\
\stackrel{+}{J}\end{array}$ & $\begin{array}{l}\mp+1 \\
=\end{array}$ & $\begin{array}{l}-+1 \\
\stackrel{+1}{\circ}\end{array}$ & $\overline{+1}_{\sim}^{+1}$ & $\overline{+}_{i}^{+1}$ & $\begin{array}{l}0 \\
+1 \\
r\end{array}$ \\
\hline$\underline{\bar{n}}$ & $\begin{array}{l}\stackrel{n}{+} \\
+1 \\
\stackrel{8}{\sigma}\end{array}$ & $\begin{array}{l}\frac{\infty}{+1} \\
\stackrel{1}{\circ} \\
\stackrel{-}{+}\end{array}$ & $\begin{array}{l}\stackrel{\omega}{\sim} \\
+1 \\
\stackrel{+}{N} \\
\stackrel{n}{N}\end{array}$ & $\begin{array}{l}\stackrel{\sim}{n} \\
++1 \\
\infty \\
\stackrel{m}{\sim}\end{array}$ & \begin{tabular}{l}
$\tau$ \\
+ \\
+ \\
\multirow{O}{0}{}
\end{tabular} & $\begin{array}{l}\stackrel{+}{+} \\
+1 \\
\stackrel{+}{\sim} \\
\leftarrow\end{array}$ & $\begin{array}{l}\varphi \\
+ \\
+1 \\
m \\
\stackrel{\nu}{N}\end{array}$ & $\begin{array}{l}\stackrel{\text { }}{+} \\
+1 \\
\stackrel{1}{n}\end{array}$ & $\begin{array}{l}0 \\
+1 \\
\infty \\
\stackrel{\sim}{\simeq}\end{array}$ & $\begin{array}{l}\text { f } \\
+1 \\
\bar{\sigma}\end{array}$ \\
\hline 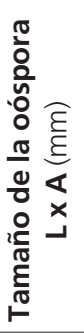 & 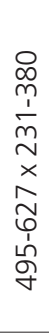 & 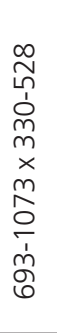 & 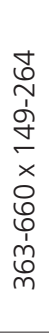 & 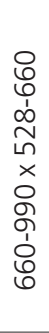 & 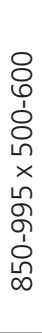 & 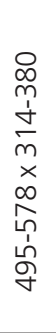 & 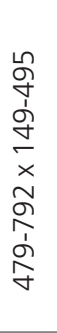 & 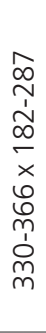 & 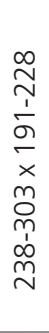 & 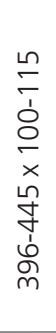 \\
\hline 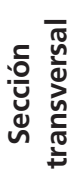 & $\begin{array}{l}\frac{\bar{\pi}}{\bar{J}} \\
\frac{\bar{U}}{U}\end{array}$ & $\begin{array}{l}\frac{\bar{\pi}}{\bar{J}} \\
\frac{\cdot}{\pi}\end{array}$ & 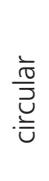 & $\begin{array}{l}\frac{\bar{\pi}}{\bar{J}} \\
\frac{\bar{U}}{\bar{U}}\end{array}$ & $\frac{\sqrt{\pi}}{\bar{J}}$ & $\begin{array}{l}\frac{\bar{\pi}}{\overline{2}} \\
\frac{\bar{U}}{\bar{n}}\end{array}$ & $\begin{array}{l}\frac{\bar{\pi}}{\bar{J}} \\
. \overline{\frac{U}{U}}\end{array}$ & $\begin{array}{l}\bar{\sigma} \\
\text { o }\end{array}$ & $\begin{array}{l}\frac{\bar{\pi}}{\bar{J}} \\
\frac{\bar{U}}{\bar{U}}\end{array}$ & $\begin{array}{l}\frac{\bar{\pi}}{\bar{T}} \\
\frac{\cdot}{\bar{U}}\end{array}$ \\
\hline 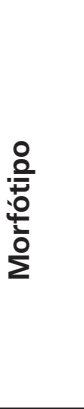 & $\begin{array}{l}\frac{\pi}{\pi} \\
\frac{\pi}{3} \\
\frac{\pi}{0} \\
\frac{\pi}{0} \\
\frac{\pi}{3}\end{array}$ & 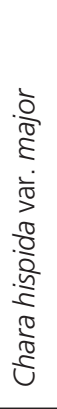 & $\begin{array}{l}\frac{0}{0} \\
\frac{0}{0} \\
0 \\
\frac{0}{0} \\
\frac{\pi}{0}\end{array}$ & 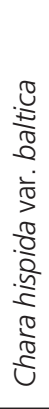 & 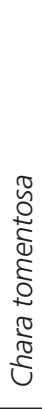 & 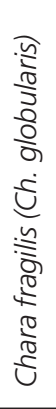 & 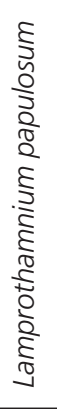 & 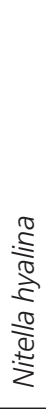 & 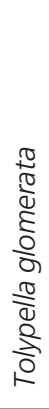 & 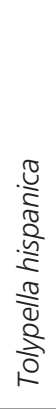 \\
\hline
\end{tabular}


Servicio Central de Soporte a la Investigación Experimental de la Universitat de València. Las oósporas se lavaron previamente con una disolución de agua y jabón al $1 \%$ y se mantuvieron en una solución de ácido clorhídrico diluido durante una noche para retirar los restos de carbonato cálcico depositados sobre la pared.

Para la identificación de las oósporas-girogonitos se recurrió a las claves de Haas (1994), Krause (1997) y Vedder (2004), se consultó la bibliografía de Cirujano y Medina (2002) y Cirujano \& al., (2007, 2008), y se compararon los ejemplares obtenidos con los de la colección de la Dra. Ingeborg Soulié-Märsche (Univ. Montpellier II) y las imágenes de Soulié-Märsche (1989). Finalmente, se cuantificó el número de oósporasgirogonitos por peso de sedimento en las diferentes capas de los testigos de sedimento.

\section{Resultados}

\section{Táxones identificados}

Basándonos en las oósporas-girogonitos procedentes de los sedimentos de la Albufera de Valencia se han identificado 10 táxones que corresponden a los siguientes géneros (Figs. 2-5, Tabla 2):

\section{Género Chara}

\section{Chara vulgaris (Fig. 3A)}

Fue la especie de este género más abundante en el sedimento (6,6 oósporas-girogonitos/gPS, de abundancia máxima). Las oósporas aparecen por primera vez a los 38-40 cm y alcanzan los $86 \mathrm{~cm}$ de profundidad. Se trata de oósporas de pequeño tamaño $(559 \times$ $297 \mu \mathrm{m}$ en promedio), color negro, con 11 espiras en promedio. La mayor parte de las oósporas estudiadas presentan columna en la base. El ápex es cóncavo y no poseen hombro.

\section{Chara hispida var. major (Fig. 3B)}

Abundancia máxima de 3,4 oósporas-girogonitos/gPS sedimento. Sus esporas se encontraron desde los 14-16 cm de profundidad del sedimento hasta los $76-78 \mathrm{~cm}$. Se trata de oósporas de gran tamaño $(881 \times$ $464 \mu \mathrm{m}$ en promedio), con 12 espiras de media, con la pared desprovista de ornamentación. Color marrón oscuro a negro brillante. Posee columna en la base y el ápex es fuertemente cóncavo y con hombro.

\section{Chara aspera (Fig. 4A)}

Su abundancia máxima fue de 2,5 oósporas-girogonitos/gPS sedimento. Las oósporas aparecen a partir de los $36-38 \mathrm{~cm}$ de profundidad y se distribuyen hasta los $87 \mathrm{~cm}$ finales. Las oósporas son de pequeño ta- maño $(549 \times 207 \mu \mathrm{m}$ en promedio), el número de estrías es de 13. Presentan el índice de isopolaridad más alto de todos los táxones del género Chara encontrados en la Albufera (ISI = 275). Color negro. No presentan columna en la base y el ápex varía de plano a cóncavo y sin hombro.

\section{Chara hispida var. baltica (Fig. 4B)}

La abundancia máxima de sus oósporas fue de 1,4 oósporas-girogonitos/gPS sedimento. Aparecen desde los $36-38 \mathrm{~cm}$ de profundidad hasta el final. Las oósporas son de gran tamaño $(660 \times 413 \mu \mathrm{m}$ en promedio $)$, con 12 espiras en promedio. Su color varía de marrón oscuro a negro. Pueden presentar columna en la base pero poco aparente y el ápex fuertemente cóncavo, con hombro. El ISI es más bajo (160) que en la var. major (190).

\section{Chara tomentosa (Fig. 4C)}

$\mathrm{Su}$ abundancia fue de 0,8 oósporas-girogonitos/gPS sedimento. Las oósporas se detectan a partir de los $36-38 \mathrm{~cm}$ de profundidad y llegan prácticamente hasta el final. Posee oósporas grandes $(941 \times 575$ $\mu \mathrm{m}$ en promedio), con 14 espiras de promedio, poco evidentes. De color marrón rojizo, con la pared transparente. Sin columna, con el ápex plano y no poseen hombro.

\section{Chara fragilis (Ch. globularis) (Fig. 4D)}

$\mathrm{Su}$ abundancia fue baja, 0,2 oósporas-girogonitos/gPS. Aparecen en niveles más profundos, desde $56-58 \mathrm{~cm}$ hasta $82-84 \mathrm{~cm}$. Oóspora de tamaño medio $(545 \times 355 \mu \mathrm{m}$ en promedio), con 11 espiras de media. Color marrón, marrón negruzco o negro. No presenta columna en la base y el ápex es convexo con hombro y la roseta redondeada.

\section{Género Lamprothamnium}

\section{Lamprothamnium papulosum (Fig. 5A)}

Fue la especie que presentó mayor número de oósporas en el sedimento, con 35,4 oósporas-girogonitos/gPS. Apareció principalmente a partir de los 50 $\mathrm{cm}$ de profundidad y su distribución alcanzó el final del testigo. Oóspora de tamaño variable $(628 \times 323$ $\mu \mathrm{m}$ en promedio), de 8 a 11 espiras. La pared de la oóspora presenta una ornamentación que varía desde papilas bastante prominentes a gránulos, con orificios centrales y redondos en ellos. En las estrías se aprecian pequeñas uñas. Color negro. No presentan columna ni hombro. Todos los girogonitos observados carecían de ápex. 


\section{Género Nitella}

\section{Nitella hyalina (Fig. 5B)}

Especie poco representada con 0,4 oósporas/gPS. Las oósporas se detectaron a partir de los 12-14 cm y se extendieron hasta los 64-66 cm. Posee oósporas redondeadas, de sección oval y tamaño pequeño $(346 \times$ $238 \mu \mathrm{m})$, con 7 espiras, con crestas poco aparentes, no aladas. Color marrón rojizo. Ornamentación de la pared finamente punteada. No forma girogonitos.

\section{Género Tolypella}

\section{Tolypella glomerata}

La abundancia de esta especie fue baja, 0,5 oósporas/gPS. Las oósporas aparecieron a partir de los 16-18 $\mathrm{cm}$ y llegaron hasta los $24-26 \mathrm{~cm}$. Oósporas globulares, de sección circular, pequeñas $(268 \times 209 \mu \mathrm{m})$, con 7 espiras. Color marrón grisáceo. No forma girogonitos.

\section{Tolypella hispanica}

Especie muy poco representada, con 0,04 oósporas $/ g P S$. Se encontró a una profundidad de $78-80 \mathrm{~cm}$.
Sus oósporas son más alargadas que las de la especie anterior, de sección circular y pequeñas $(445 \times 100$ $\mu \mathrm{m})$, con 7 espiras y velo en las estrías prominentes. Color marrón rojizo oscuro. No forma girogonitos.

Por último, se identificó un tipo de oóspora bastante abundante, 6 oósporas-girogonitos/gPS sedimento a partir los $50 \mathrm{~cm}$ de profundidad del sedimento, $\mathrm{cu}-$ yas características no corresponden con ninguno de los descritos en la bibliografía, y que en nuestra opinión podría tratarse de una variedad de Chara vulgaris o de Ch. aspera.

Al realizar el estudio morfométrico de 180 oósporas-girogonitos y representar la relación longitud/anchura (Fig. 6A) se separaron claramente las de gran tamaño, que corresponden a Chara hispida var. major y var. baltica y $C h$. tomentosa. Otras esporas quedan más solapadas en cuanto a sus características morfométricas, a excepción de las de los géneros Nitella y Tolypella, que se distinguen de las restantes por su menor tamaño como se ha indicado anteriormente. Para las oósporas y girogonitos de las especies más abundantes se han estudiado las relaciones alométricas entre la longitud y la anchura (Fig. 6B). Tanto las oósporas
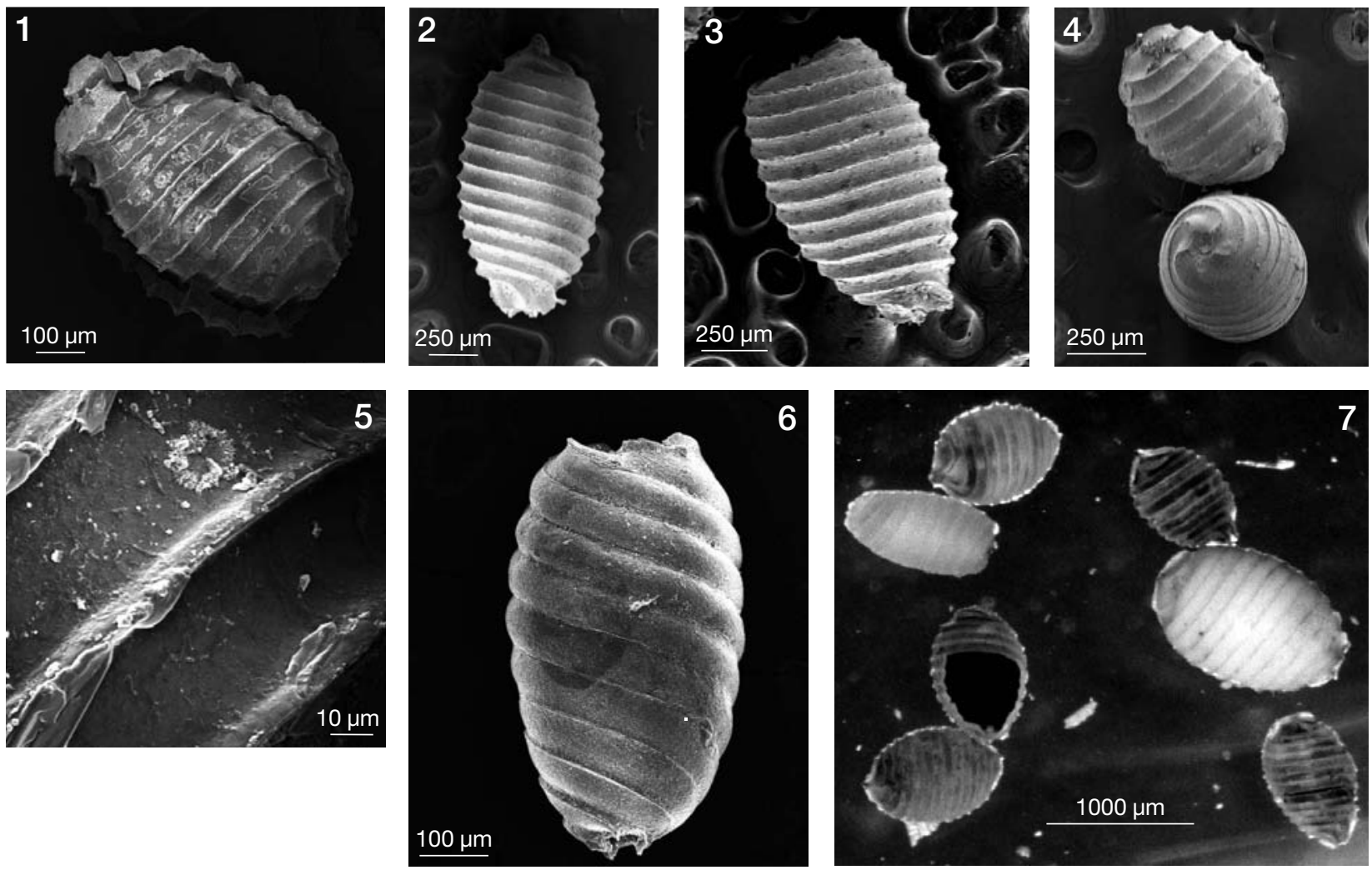

Fig. 2. Microfotografías al microscopio electrónico de barrido (1-6) y con estereomicroscopio (7) de girogonitos del sedimento de la Albufera de Valencia: 1, girogonito de Chara vulgaris fragmentado donde se observa la oóspora en su interior; 2, 3, girogonitos de Ch. hispida var. major; 4, girogonitos de Ch. vulgaris; 5, detalle de la pared de una oóspora; 6, girogonito de Lamprothamnium papulosum. 
como los girogonitos de Chara hispida var. major y de L. papulosum presentaron relaciones alométricas estadísticamente significativas, así como los girogonitos de Ch. hispida var. baltica. En cambio, ni las oósporas ni los girogonitos de Chara vulgaris presentaron tipo alguno de relación entre la longitud y la anchura.

\section{Oósporas-girogonitos en el perfil vertical del sedimento}

Las oósporas y girogonitos se empezaron a detectar en cierta cantidad a partir de los $14 \mathrm{~cm}$ de profundidad del sedimento (Fig. 7), aunque en los $2-4 \mathrm{~cm}$ superiores ya aparecieron algunas oósporas aisladas, lo
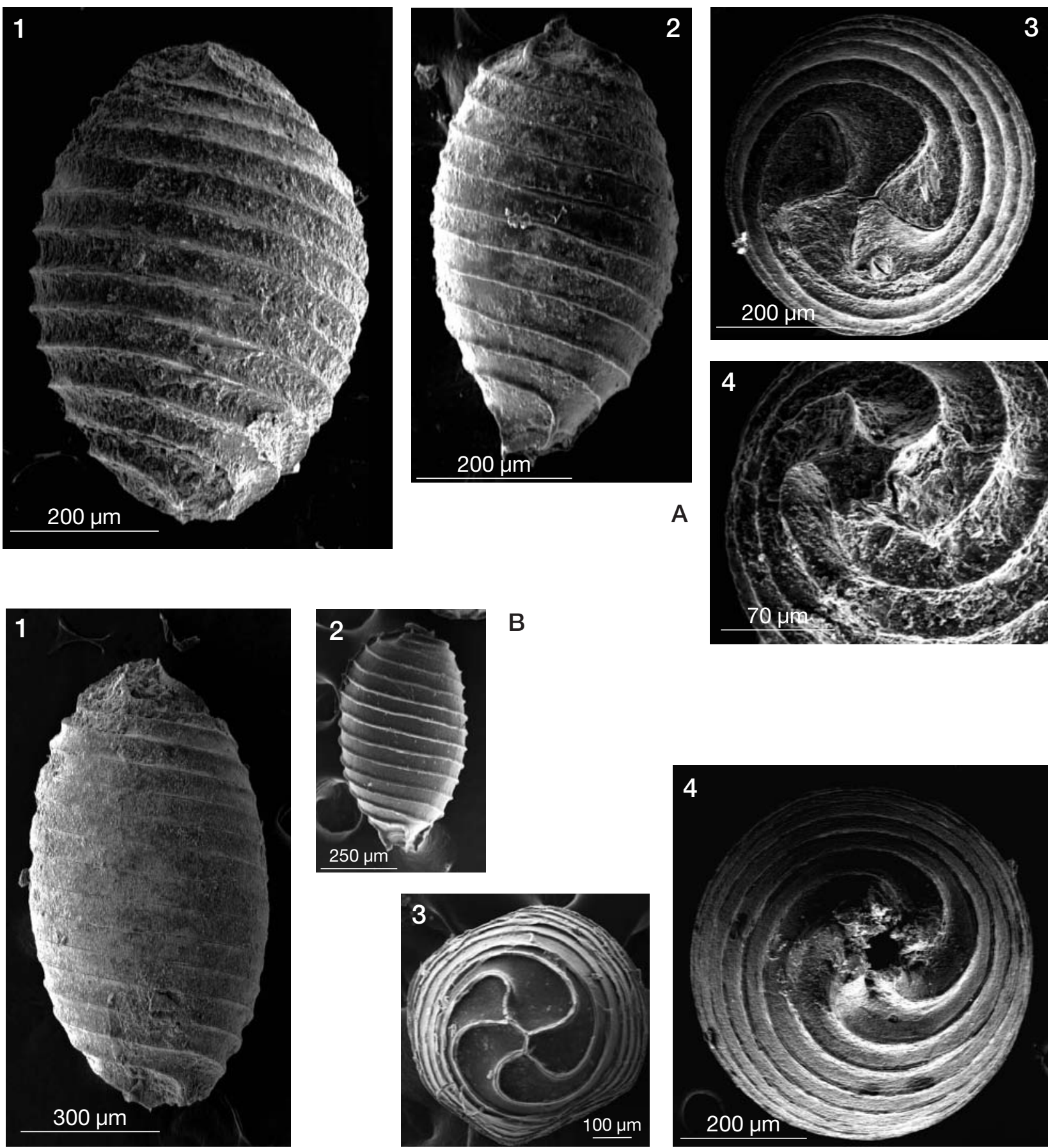

B
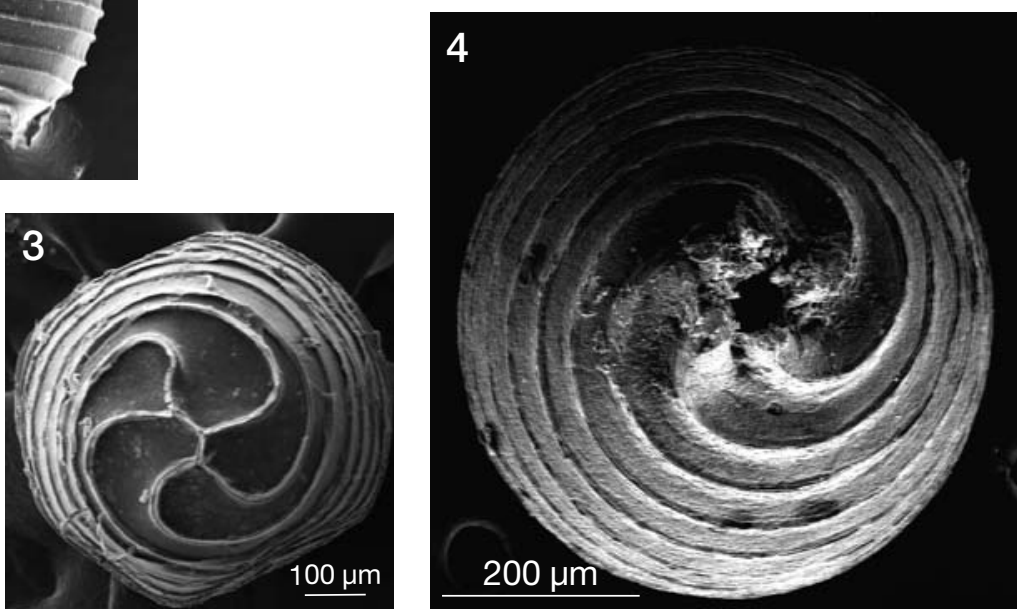

Fig. 3. Microfotografías al microscopio electrónico de barrido correspondientes a fructificaciones de diferentes especies de carófitos encontradas en el sedimento de la Albufera de Valencia. A, Chara vulgaris: 1, vista lateral de un girogonito; 2, vista lateral de una oóspora; 3, vista apical de un girogonito; 4, vista basal de un girogonito. B, Ch. hispida var. major: 1, vista lateral de un girogonito; 2, vista lateral de una oóspora; 3, vista apical de una oóspora; 4, vista basal de un girogonito. 


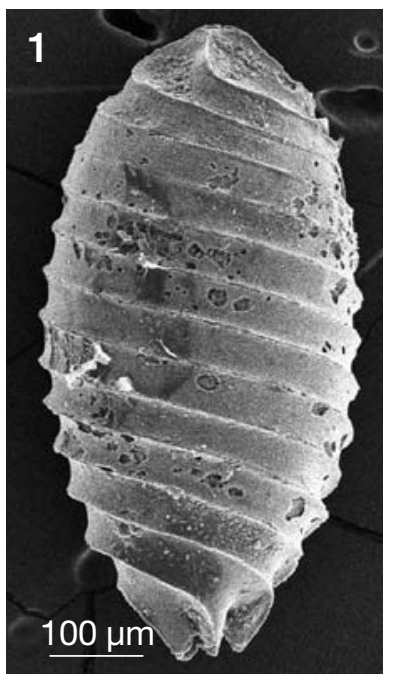

A
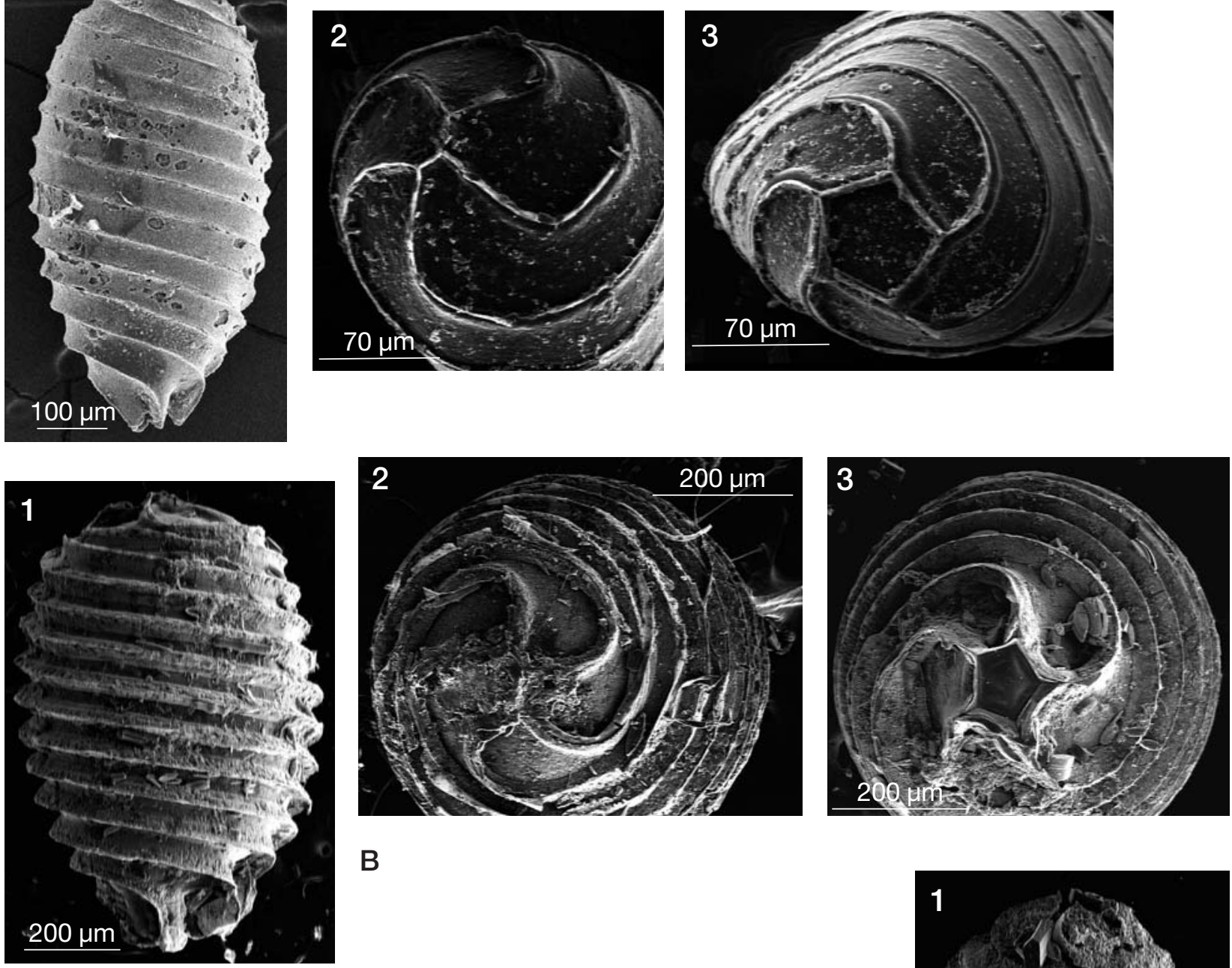

B
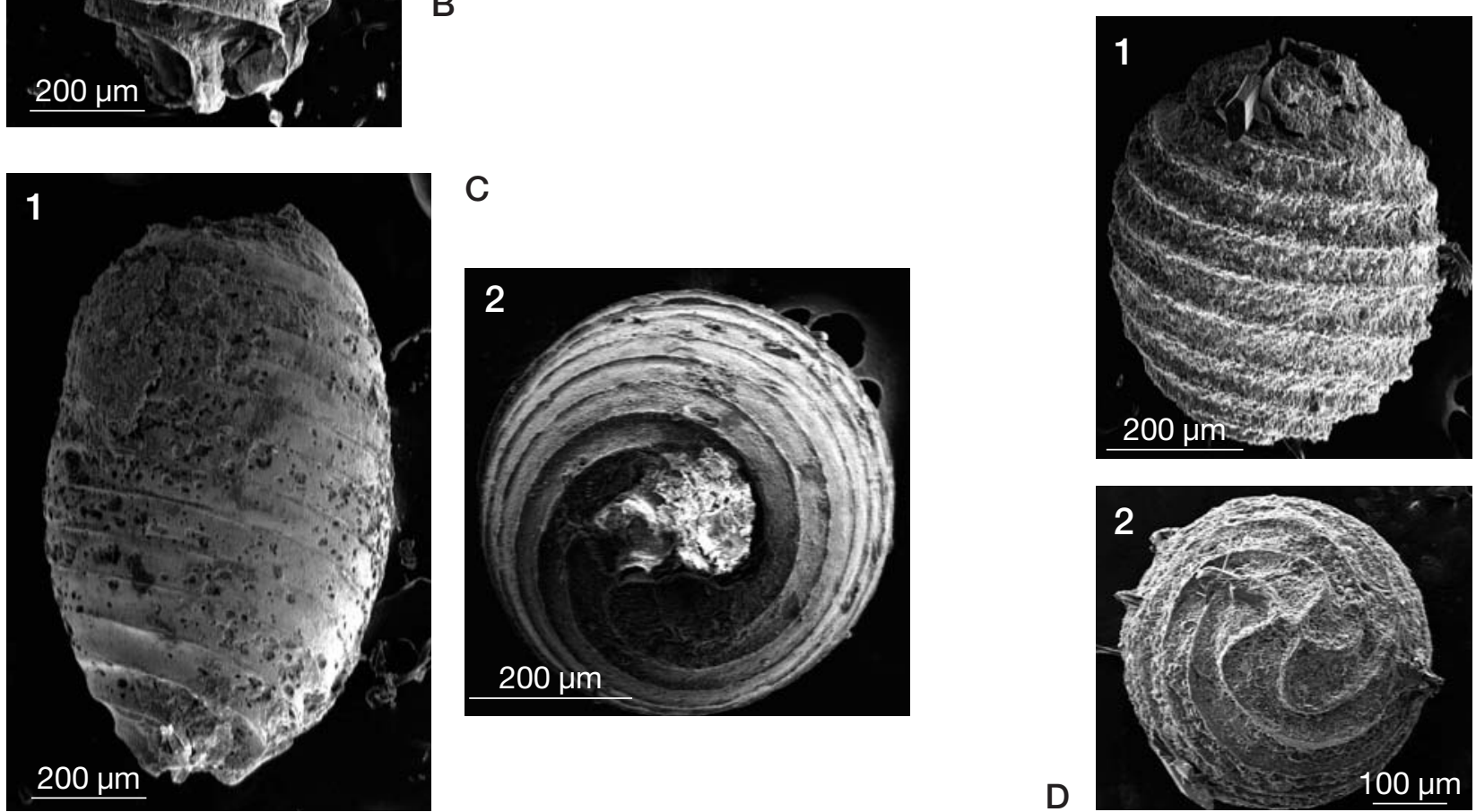

C
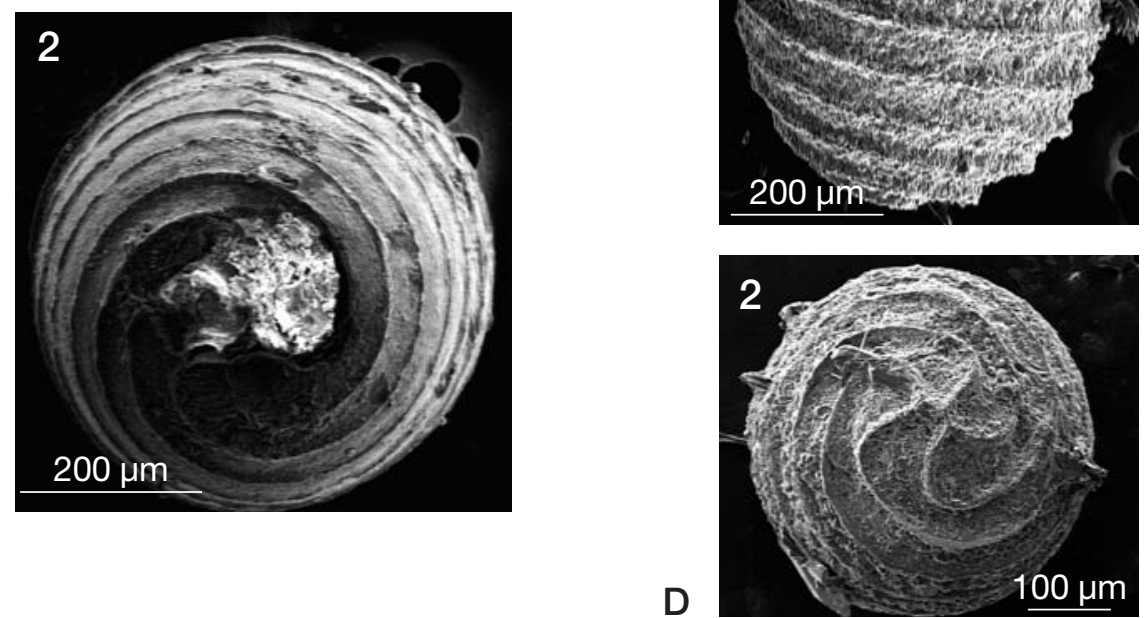

Fig. 4. Microfotografías al microscopio electrónico de barrido correspondientes a fructificaciones de diferentes especies de carófitos encontradas en el sedimento de la Albufera de Valencia. A, girogonito de Chara aspera: 1, vista lateral; 2, vista apical de una oóspora; 3, vista basal de una oóspora. B, girogonito de Ch. hispida var. baltica: 1, vista lateral; 2, vista apical; 3, vista basal. C, girogonito de Ch. tomentosa: 1, vista lateral; 2, vista apical. D, girogonitos de Ch. globularis: 1, vista lateral; 2, vista apical. 
A
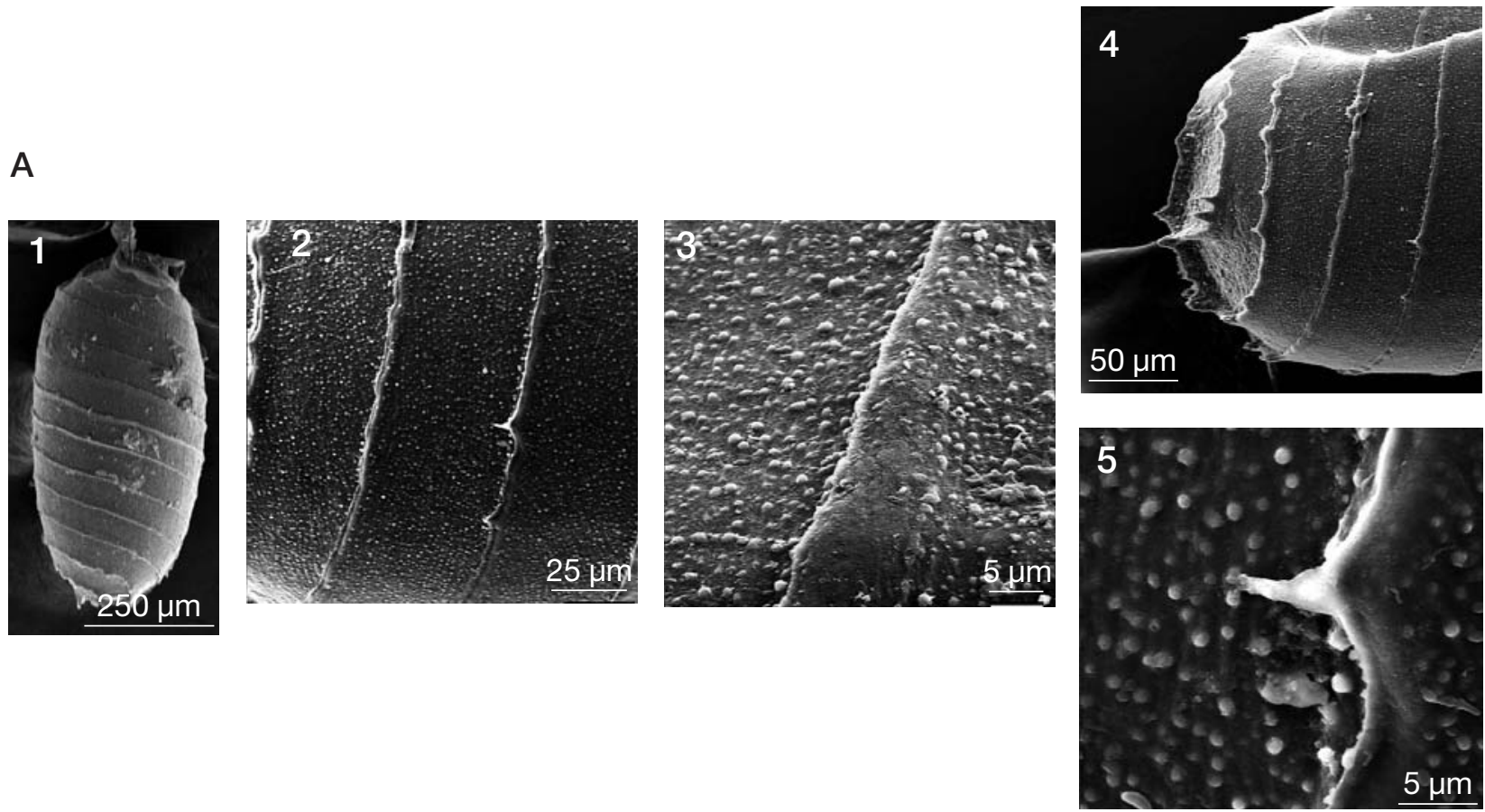

B
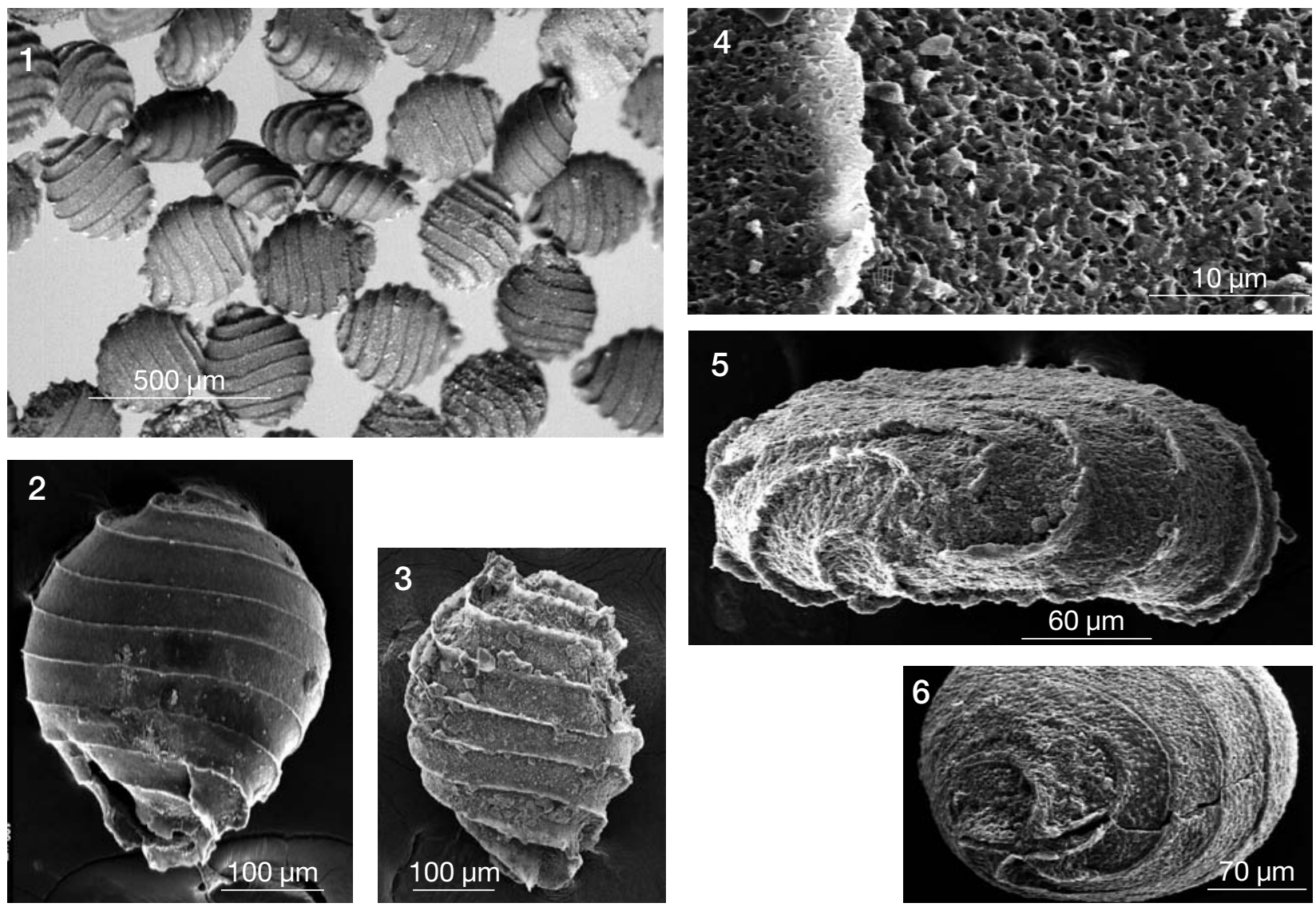

Fig. 5. Microfotografías al microscopio electrónico de barrido correspondientes a fructificaciones de diferentes especies de carófitos encontradas en el sedimento de la Albufera de Valencia. A, oósporas de Lamprothamnium papulosum: 1, vista lateral de una oóspora; 2, 5, detalles de la pared de la oóspora y de las uñas de las estrías. B, oósporas de Nitella hyalina: 1, vistas con estereomicroscopio; 2, 3, vista lateral de dos oósporas; 4, detalle de la ornamentación de la pared de la oóspora; 5, vista basal; 6, vista apical. 


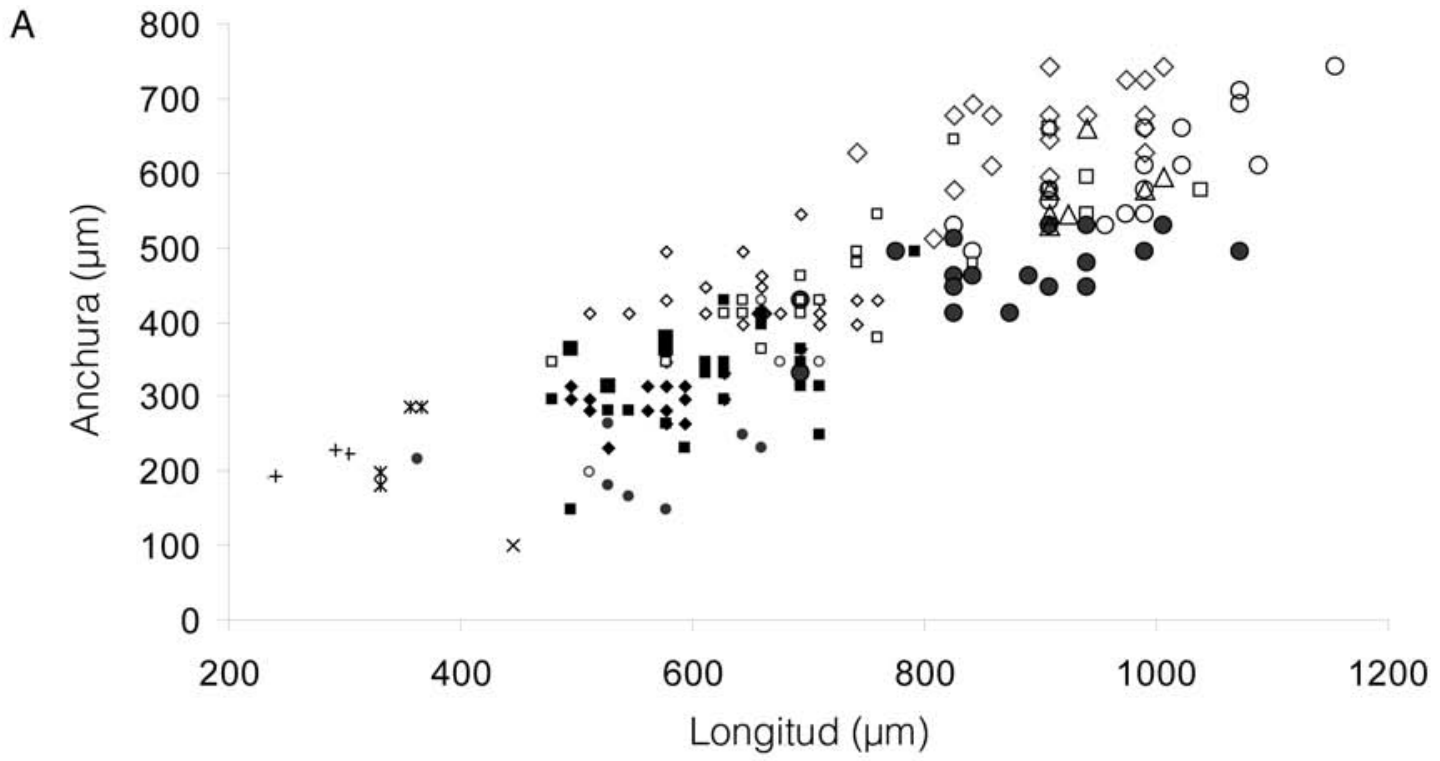

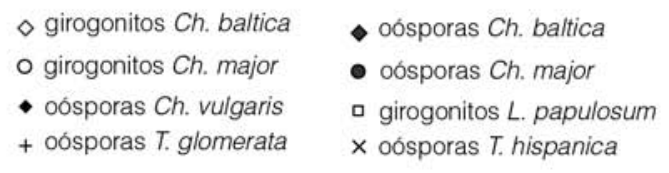

$\diamond$ girogonitos Ch. baltica

- oósporas Ch. aspera

- oóspora Ch. globularis

- girogonitos Ch. vulgaris

* oósporas N. hyalina
- oósporas Ch. vulgaris

$\times$ oósporas T. hispanica
B
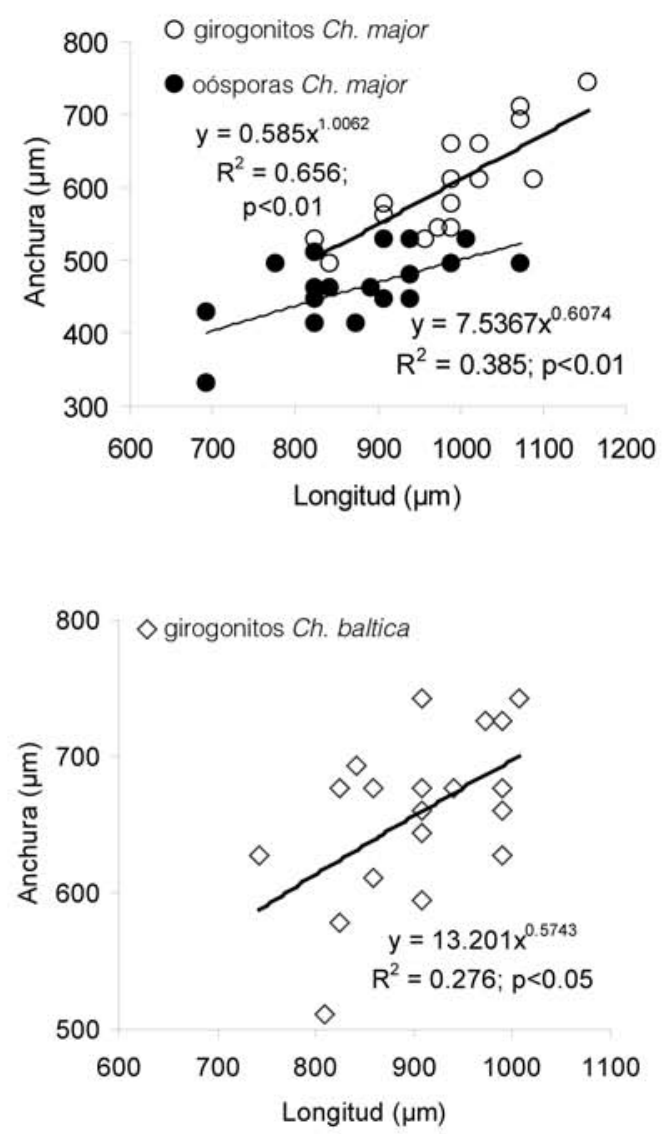
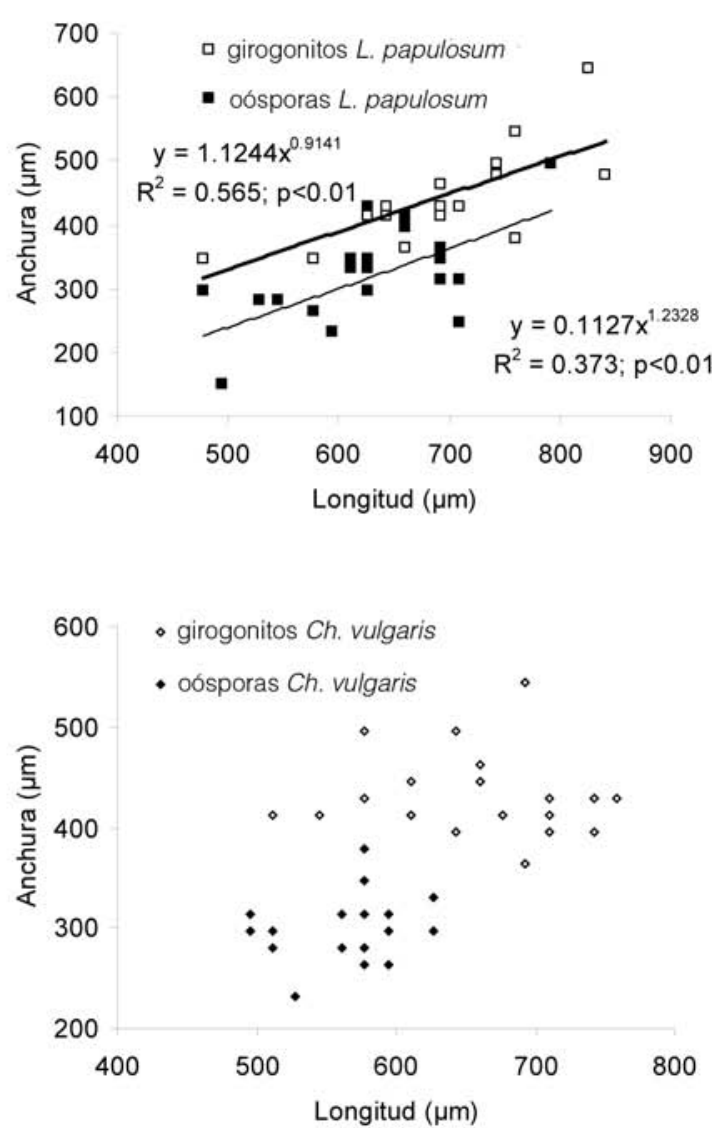

Fig. 6. A, Distribución de tamaños (longitud y anchura) de las oósporas y girogonitos de las distintas especies de carófitos del sedimento de la Albufera de Valencia. B, Relaciones entre la longitud y la anchura de oósporas y girogonitos de algunas especies $(n=20)$. 
que puede deberse a procesos de bioturbación o mezcla del sedimento. Las concentraciones más elevadas (alrededor de 35 oósporas-girogonitos/gPS sedimento; Fig. 3A) se encontraron a los 64-66 cm y desde los 78 $\mathrm{cm}$ hasta el final del testigo de sedimento $(87 \mathrm{~cm})$. Las oósporas más abundantes a estas profundidades pertenecían a Lamprothamnium papulosum. Algunas oósporas de las capas de sedimento de $28-30 \mathrm{~cm}$ y $40-42 \mathrm{~cm}$ de profundidad eran todavía viables, pues germinaron durante unas experiencias de germinación con sedimento de la Albufera intacto (datos no publicados).

En las capas más superficiales del sedimento (16-26 $\mathrm{cm}$ ) predominaban los girogonitos (Fig. 3B), en cambio en las capas más profundas dominaron las oósporas sin cubierta de carbonato cálcico.

A

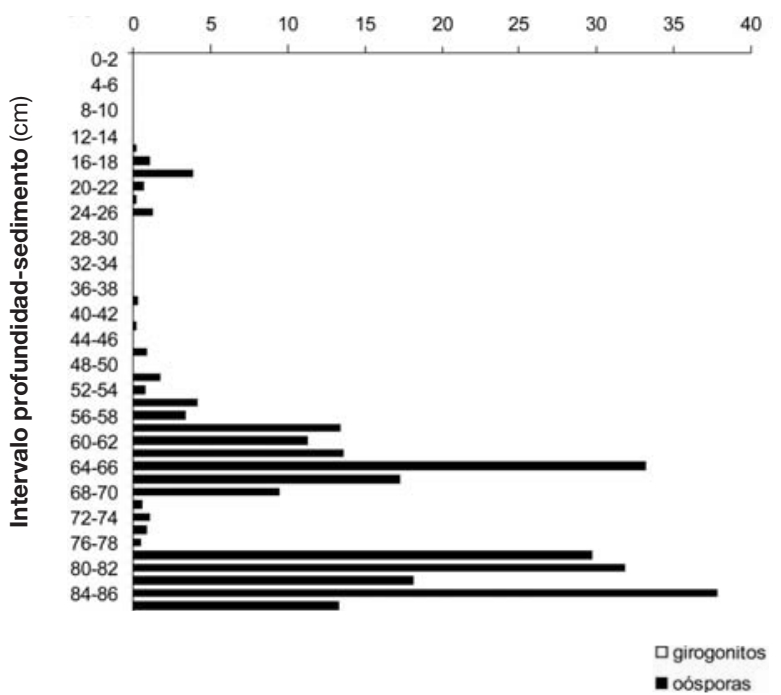

B Porcentaje de oósporas y girogonitos

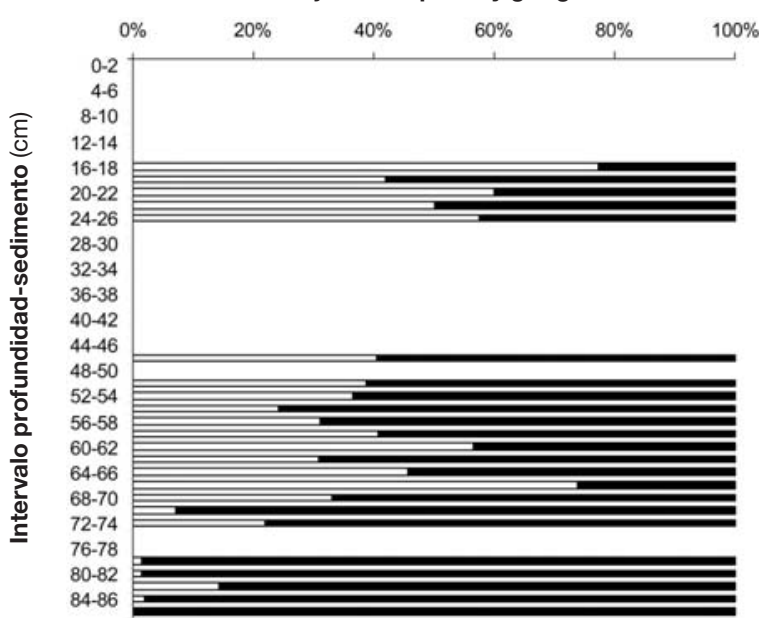

Fig. 7. A, Distribución en profundidad de la abundancia de fructificaciones de carófitos (oósporas y girogonitos) en el sedimento del punto 1 de la Albufera de Valencia. B, Proporción de oósporas y girogonitos.

\section{Discusión}

Existen algunas referencias, más o menos antiguas, de los carófitos que vivieron en la Albufera de Valencia, que coinciden en parte con las especies descritas en nuestro estudio a partir de las oósporas encontradas en el sedimento (Tabla 3).

Además de las especies citadas hemos identificado, a partir de las esporas del sedimento, a Chara vulgaris y Tolypella hispanica, esta última escasamente representada, por lo que las formaciones de carófitos que se desarrollaron en la laguna estuvieron constituidas, al menos, por 12 táxones.

La identificación de las oósporas de Chara puede resultar difícil, pues las características morfológicas (tamaño, color, número de espiras, formas del ápice y de la base, ornamentación, etc.) pueden variar en un mismo táxon e incluso solaparse con otros próximos (Ray \& al., 2000). Esto no ocurre con las esporas de los géneros Nitella y Tolypella, en los que la ornamentación de la pared tiene caracteres distintivos que permiten su identificación (Cirujano \& al., 2008). No obstante, algunas relaciones morfométricas entre la longitud y anchura de las esporas tienen interés taxonómico, y los caracteres morfológicos que hemos analizado han mostrado ser útiles para la separación de los táxones incluidos en el género Chara (Ray \& al., 2001; Mandal \& al., 2008).

La diversidad de la flora carofítica descrita en este estudio hay que referirla a un periodo de tiempo largo, que se determinará tras la datación completa de los sedimentos, y que sin duda incluye periodos más salinos, que se ponen de manifiesto por la presencia de táxones propios de aguas salinas y por tanto claramente halófilos, como Lamprothamnium papulosum (la especie de carófito más halotolerante -20-40 g/1- entre las Caráceas; Soulié-Märsche, 1998) y Tolypella bispanica (Martínez-Taberner y Moyá, 1991; Cirujano \& Medina, 2002; Elkhiati \& al., 2004; García \& Chivas, 2004; Cirujano \& al., 2007, 2008), y otros más dulces en los que proliferarían Chara fragilis (Ch. globularis) y Nitella byalina (Cirujano \& Medina, 2002; Cirujano \& al., 2007, 2008). A éstas hay que añadir otras como Chara vulgaris o el grupo $C h$. hispida, que tienen mayor amplitud ecológica. La diversidad de carófitos encontrada en la Albufera de Valencia es semejante a la indicada en otros humedales litorales mediterráneos como la Albufera de Mallorca, de la que Martínez-Taberner \& Moyà (1991) refieren 11 especies de carófitos.

A partir de los restos en el sedimento de la flora carofítica podemos interpretar la sucesión de especies a lo largo del tiempo en la Albufera de Valencia (Fig. 8). Cuando la laguna poseía una elevada y fluctuante salinidad (por fuerte conexión con el mar; Sanchis-Ibor, 
Tabla 3. Referencias de los carófitos citados de la Albufera de Valencia. (* En sedimento).

\begin{tabular}{|l|l|}
\hline Táxon & Autores, año \\
\hline Chara hispida (Ch. aculeolata) & Prósper, 1910; Corillion, 1962; Guerlesquin, 1963 \\
\hline Chara hispida f. polyacantha & Corillion, 1962 \\
\hline Chara hispida var. baltica (Ch. baltica) & Corillion, 1962 \\
\hline Chara hispida var. major (Ch. intermedia) & Prósper, 1910 \\
\hline Chara tomentosa (Ch. ceratophylla) & Prósper, 1910 \\
\hline Chara fragilis (Ch. globularis) & Dafauce, 1975 \\
\hline Chara aspera & Corillion, 1962; Guerlesquin, 1963; Boira \& Carretero, 1985 \\
\hline Nitella hyalina & Prósper, 1910; Boira \& Carretero, 1985 \\
\hline Tolypella glomerata & Prósper, 1910; Comelles, 1982 \\
\hline Lamprothamnium papulosum* & Dafauce, 1975 \\
\hline
\end{tabular}

2001) la comunidad de carófitos estaría dominada por Lamprothamnium papulosum, la especie que presentó una mayor densidad de oósporas en el sedimento, acompañada de Chara aspera, Ch. hispida var. baltica y Tolypella hispanica. Un ensamblado semejante de especies ha sido descrito en un testigo de sedimento de una laguna de aguas salobres de la costa atlántica de Marruecos (Elkhiati \& al., 2004). A medida que el agua de la laguna se fue dulcificando por las transformaciones sufridas para el cultivo del arroz principalmente (Sanchis-Ibor, 2001), la comunidad de carófitos cambiaría en el sentido de que Chara vulgaris podría haber sido la especie dominante y estar acompañada de Ch. hispida var. major, Lamprothamnium papulosum y Ch. hispida var. baltica. A partir de un momento dado, las oósporas y girogonitos de la especie Lam-

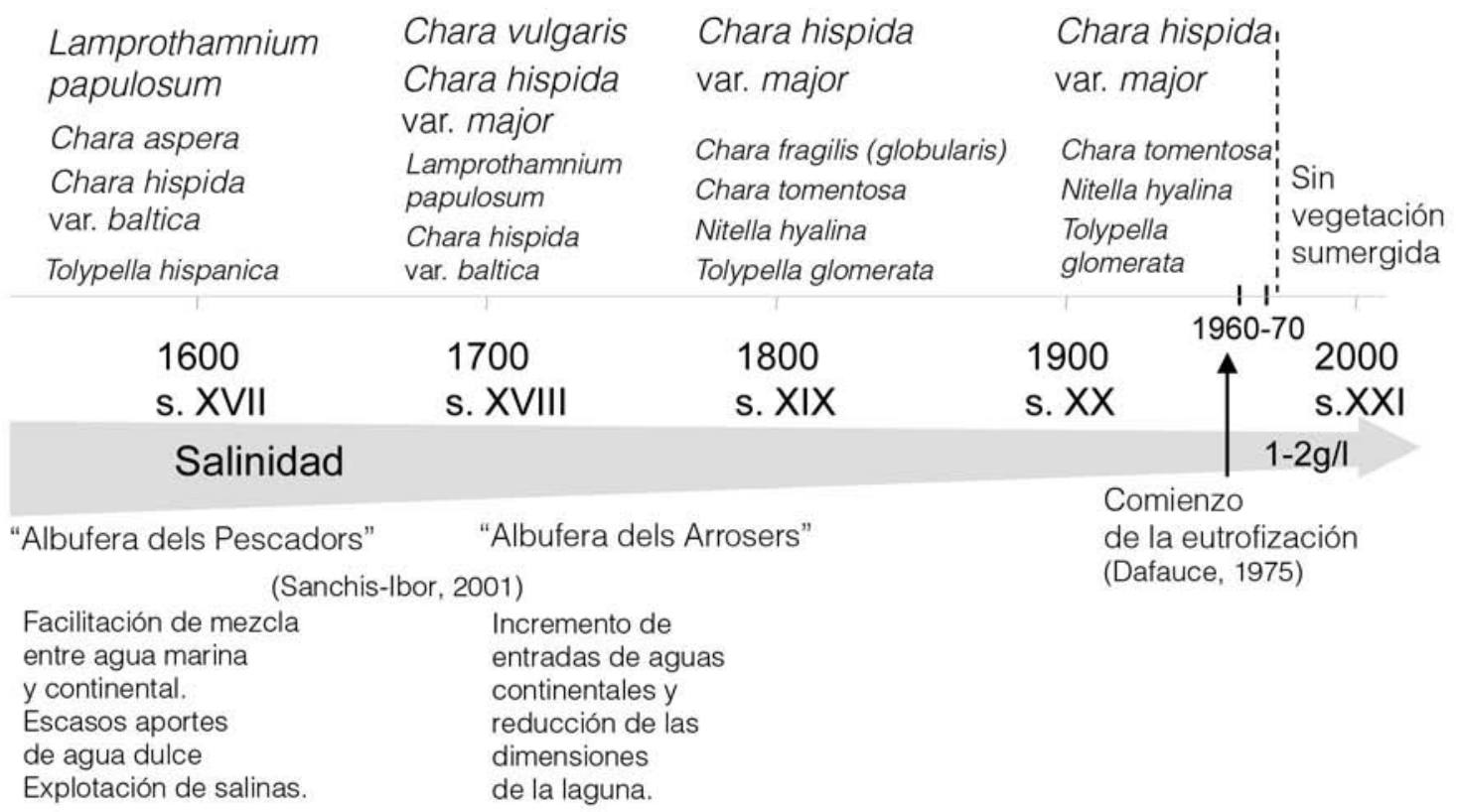

Fig. 8. Esquema gráfico que ilustra los cambios experimentados en las comunidades de carófitos a lo largo del tiempo en la Albufera de Valencia interpretados a partir de la información obtenida de las oósporas y girogonitos de los sedimentos. El mayor tamaño de la letra en el nombre de las especies indica mayor abundancia de fructificaciones en el sedimento. 
prothamnium papulosum desaparecen por completo en los sedimentos, lo que indicaría que el agua de la laguna habría bajado de los $20 \mathrm{~g} / 1$ de salinidad, umbral mínimo para que esta especie fructifique (SouliéMärsche, 1998). En aquel momento la comunidad de carófitos estaría formada por la dominante Chara bispida var. major y en menor medida por Ch. fragilis (globularis), Ch. tomentosa, Nitella byalina y Tolypella glomerata. Acercándose hacia los años setenta (y con ello al avance de la eutrofización; Dafauce, 1975), la comunidad de carófitos presentaría un claro predominio de la especie Ch. hispida var. major (sus oósporas fueron las últimas en desaparecer en las capas superiores del sedimento), y Ch. tomentosa, Nitella byalina y Tolypella glomerata estarían escasamente representadas.

En este estudio se ha observado una relación directa entre cantidad y diversidad de oósporas y profundidad del sedimento. No se encontraron oósporas en cantidades significativas hasta los $14 \mathrm{~cm}$ de profundidad del sedimento (nivel correspondiente a $1974 \pm 5$, según datación del sedimento; Rodrigo \& al., en preparación), lo que indica que el proceso de eutrofización que padece la laguna durante al menos los últimos 45 años (Tabla 1; Dafauce, 1975; Soria \& al., 1987) afectó al desarrollo de los carófitos hasta producir su extinción. Por otro lado, la información aquí obtenida tiene una clara aplicación práctica, pues resulta valiosa en el caso de que la Albufera recuperara su condición de laguna de aguas limpias y claras o si se desea plantear una restauración de ambientes acuáticos de las inmediaciones de la laguna. Se han obtenido cultivos de los carófitos que habitaron la Albufera de Valencia a partir de la germinación de las oósporas encontradas en los sedimentos. Dichos cultivos podrán ser utilizados en la restauración ambiental de zonas colindantes a la laguna que se planea llevar a cabo (ambientes en los que se pretende conseguir una buena calidad del agua), de forma que se podría recrear parte de la comunidad de carófitos que poblaba la Albufera antes del periodo de eutrofización que la misma padece.

\section{Agradecimientos}

Los autores agradecen a Joan Miquel Benavent (Oficina Técnica Devesa-Albufera), Fidel Rubio (Laboratorio Ecología Integrativa, ICBiBE, UV) y William Colom (Innovació Ambiental S.L.) la ayuda prestada en la toma de sedimentos, así como la colaboración de los técnicos del SCSIE del servicio de microscopía electrónica de la UV. La Dra. M.J. Carmona (Ecología Evolutiva, ICBiBE) amablemente nos prestó el sistema hidráulico de corte del sedimento. Este trabajo ha sido financiado por el proyecto GV2007084 (Conselleria d'Empresa, Universitat i Ciència, D. Gral. d'Investigació i Transferència Tecnològica) otorgado a M.A. Rodrigo. Fabiola Barraclough (Interglobe Languages) amablemente supervisó el inglés del Abstract.

\section{Referencias bibliográficas}

Arévalo, C. 1916. Introducción al estudio de los cladóceros del plankton de la Albufera de Valencia. Trabajos del Laboratorio de Hidrobiología Española 1. Anales del Instituto General y Técnico de Valencia 1.

Blindow, I. 1992. Decline of charophytes during eutrophication: comparison with angiosperms. Freshwater Biology 28: 9-14.

Boira, H. \& Carretero, J.L. 1985. Las carofíceas de las provincias de Castellón y Valencia. Collectanea Botanica (Barcelona) 16: 13-18.

Bonis, A., \& Grillas, P. 2002. Deposition, germination and spatiotemporal patterns of charophyte propagule banks: a review. Aquatic Botany 72: 235-248.

Cirujano, S. \& Medina, L. 2002. Plantas acuáticas de las lagunas y humedales de Castilla-La Mancha. Real Jardín Botánico, CSIC; Junta de Comunidades de Castilla-La Mancha.

Cirujano, S., García Murillo, P., Meco, A. \& Fernández Zamudio, R. 2007. Los carófitos ibéricos. Anales del Jardín Botánico de Madrid 64: 87-102.

Cirujano, S., Cambra, J., Sánchez Castillo, P.M., Meco, A. \& Flor Arnau, N. 2008. Flora ibérica algas continentales. Carófitos. Real Jardín Botánico, CSIC.

Combroux, I., Bornette G., Willby N.J. \& Amoros, C. 2001. Regenerative strategies of aquatic plants in disturbed habitats: the role of the propagule bank. Archiv für Hydrobiologie 152: 215-235.

Comelles, M. 1982. El gènere Tolypella a Espanya. Collectanea Botanica (Barcelona) 13: 777-781.

Corillion, R. 1962. Nouvelle contribution á l'étude des Charophycées de la Péninsule Ibérique et du Maroc occidental. Bulletin de la Société Scientifique de Bretagne 37: 65-80.

Dafauce, C. 1975. La Albufera de Valencia. Un estudio piloto. Monografías del Instituto para la Conservación de la Naturaleza, ICONA 4: 1-127.

De Winton, M.D., Clayton, J.S. \& Champion, P. 2000. Seedling emergence from seed banks of 15 New Zealand lakes with contrasting vegetation histories. Aquatic Botany 66: 181-194.

De Winton, M.D., Casanova, M.T. \& Clayton, J.S. 2004. Charophyte germination and establishment under low irradiance. Aquatic Botany 79: 175-187.

Elkhiati, N., Soulie-Märsche, I., Gemayel, P., Flower, R. \& Ramdani, M. 2004. Recent environmental changes at Sidi Bou Rhaba Lake (Morocco) inferred from fossil Charophyte gyrogonites. Cryptogamie, Algologie 25: 175-188.

García, A. \& Chivas, A.R. 2004. Quaternary and extant euryhaline Lamprothamnium Groves (Charales) from Australia: Gyrogonite morphology and paleolimnological significance. Journal of Paeolimnology 31:321-341.

García-Roger, E.M., Carmona, M.J. \& Serra, M. 2006. Hatching and viability of rotifer diapausing eggs collected from pond sediments. Freshwater Biology 51: 1351-1358.

Guerlesquin, M.1963. Contribution à l'étude chromosomique des charophycées d'Europe occidentale et d'Afrique du Nord (II). Revue Générale de Botanique 70: 355-370.

Julià, R., Burjachs, F., Dasí, M.J., Mezquita, F., Miracle, M.R., Roca, J.R., Seret, G. \& Vicente, E. 1998. Meromixis origin and recent trophic evolution in the Spanish mountain lake La Cruz. Aquatic Sciences 60: 279-299.

Haas, J.N. 1994. First identification key for charophyte oospores from central-Europe. European Journal of Phycology 29: 227235.

Horn af Rantzien, H. 1956. Morphological terminology relating to female Charophyte gametangia and fructifications. Botanical Notes, Stockholm 109/2: 212-259.

Krause, W. 1997. Charales (Charophyceae) In: Ettl, H., Gärtner, H. Heynig H. \& Mollenhauer, D. (eds.), Süßwasserflora von Mitteleuropa 18. Stuttgart. 
Kufel, L. \& Kufel, I. 2002. Chara beds acting as nutrient sinks in shallow lakes-a review. Aquatic Botany 72: 249-260.

Mandal, D.K., Ojha, S.N. \& Ray, S. 2008. Species-specificity of oospore dimensions in three ecorticate species of Chara (Charales, Charophyceae). Aquatic Botany 88: 181-183.

Martínez-Taberner, A. \& Moyà, G. 1991. Water chemistry tolerance of Charophytes in a Mediterranean coastal marsh. Nova Hedwigia 52: 113-129.

Miracle, M.R., Soria, J.M., Vicente, E. \& Romo, S. 1987. Relaciones entre la luz, los pigmentos fotosintéticos y el fitoplancton en la Albufera de Valencia, laguna litoral hipertrófica. Limnetica 3: 25-34.

Pardo, L. 1942. La Albufera de Valencia. Biología de las aguas continentales II. Instituto Forestal de Investigaciones y Experiencias. Madrid.

Prósper, E.R. 1910. Las carófitas de España. Singularmente las que crecen en sus estepas. Madrid.

Ray, S., Pekkari, S. \& Snoeijs, P. 2000. Oospore dimensions and wall ornamentation patterns in Swedish charophytes. Nordic Journal of Botany 21: 207-224.

Romo, S., Villena, M.J., Sauquillo, M. Soria, J.M., Jiménez, M. Alfonso, T., Vicente, E. \& Miracle, M.R. 2005. Response of a shallow Mediterranean lake to nutrient diversion: does it follow similar patterns as in northern shallow lakes? Freshwater Bio$\log$ 50: 1706-1717.

Sanchis-Ibor, C. 2001. Regadiu i canvi ambiental a l'Albufera de València. Publicaciones de la Universitat de València, Departament de Geografia i Centre Valencià del Reg (UPV). València.

Serra, M., Miracle, M.R. \& Vicente, E. 1984. Interrelación entre unos parámetros físicoquímicos y biológicos de la Albufera de Valencia. Limnetica 1: 9-19.

Soria, J.M. 1997. Estudio limnológico de los ecosistemas acuáticos del Parc Natural de l'Albufera de Valencia. Tesis doctoral. Universitat de València.
Soria, J.M. \& Vicente, E. 2002. Estudio de los aportes hídricos al parque natural de la Albufera de Valencia. Limnetica 21: 105-115.

Soria, J.M., Miracle, M.R. \& Vicente, E. 1987. Aporte de nutrientes y eutrofización de la Albufera de Valencia. Limnetica 3: 227 242.

Soulié-Märsche, I. 1989. Étude comparée de gyrogonites de Charophytes actuelles et fossiles et phylogénie des genres actuels. Millau, France.

Soulié-Märsche, I. 1998. Fossil Lamprothamnium papulosum (Charophyta), a biomarker for seasonal rainfall in northern Mauritania. Paleoecology of Africa 25: 65-76.

Soulié-Märsche, I. 2008. Charophytes, indicators for low salinity phases in North African sebkhet. Journal of African Earth Science 51: 69-76.

Van den Berg, M., Scheffer, S.M. \& Coops, H. 1998. The role of Characean algae in the management of eutrophic shallow lakes. Journal of Phycology 34: 750-756.

Van den Berg, M.S., Coops, H. \& Simons, J. 2001. Propagule bank buildup of Chara aspera and its significance for colonization of a shallow lake. Hydrobiologia 462: 9-17.

Vandekerkhove, J., Declerck, S., Brendonck, L., Conde-Porcuna, J.M., Jeppesen, E., Johansson, L.S. \& De Meester, L. 2005. Uncovering hidden species: hatching diapausing eggs for the analysis of cladoceran species richness. Limnology and Oceanography-Methods 3: 399-407.

Vedder, F. 2004. Morphologie und Taxonomie rezenter und subfossiler Characeen-Oosporen aus der Ostsee. Rostocker Meeresbiologische Beiträge 13: 43-54.

Editor asociado: A. Flores Recibido: 23-I-2009

Aceptado: 30-IV-2009 